\title{
Gesture and the sonic event in Karnatak music
}

\author{
LARA PEARSON \\ Durham University
}

\begin{abstract}
This paper presents an analysis of the relationship between gesture and music in the context of a Karnatak vocal lesson recorded in Tamil Nadu, South India in September 2011. The study aims to examine instances of correspondence between gesture and sonic event that occur during the lesson. Through this analysis the paper aims to contribute to the wider debate on the factors that determine gesture. Shape and trajectory are used in this study as means of describing and comparing gestures. The teacher's hand movements are tracked and traced rendering the gestures as static shapes in still images, and developing lines in moving images. The correspondences found between gestures and sonic features are discussed in relation to the physical movement required to produce the music. In addition, the circumstances in which correspondence is not found are analyzed and the extent to which the dynamic form of gesture is also influenced by the phrase as a whole is emphasized.
\end{abstract}

Submitted 2013 January 12; accepted 2013 June 2.

KEYWORDS: gesture, South Indian music, shape, movement

\section{BACKGROUND TO THE STUDY}

MUSIC and gesture has been an active area of research in recent years, with the publication of edited volumes by Godøy and Leman (2010), and Gritten and King (2006, 2011). Within this field of inquiry Indian music has been prominent. Clayton, Leante and Rahaim have each presented studies on gesture in Hindustani music based on ethnographic research and video analysis (see Clayton, 2005, 2007; Leante, 2009; Rahaim, 2008, 2012; and Fatone, Clayton, Leante, \& Rahaim, 2011). In this body of work, gesture has been used, for example, to discuss the audience's experience of metrical structure (Clayton, 2007), the imagery used to describe a $r \bar{a} g a$ (Leante, 2009), and the concept of $r \bar{a} g a$ as a space through which music and the body moves (Fatone et al., 2011, p. 212). Factors that influence the dynamic form of gesture in music performance have been discussed by each of the three authors. Gestures can be seen to relate to pulse, pitch, communication with fellow performers and the audience, and to analogies of motion such as a bouncing ball or the tying of a knot (Fatone et al., 2011). This paper seeks to contribute to discussion of the factors that determine gesture through an analysis of a vocal lesson in the South Indian, Karnatak musical style.

The video examined here was recorded in September 2011 in the pilgrimage town of Srirangam, Tamil Nadu. It shows the violinist and vocalist T.K.V. Ramanujacharlu, a top graded staff artist at All India Radio, teaching äläpana in rāga śankaräbharanam to an experienced vocal student.[1] I had been studying with T.K.V Ramanujacharlu (hereafter TKV) as part of my research into rāga àlappana. The topic of gesture had not been discussed prior to this video recording, and therefore TKV's hand movements were unlikely to have been tailored to the event. Preliminary observation of the video indicated that many gestures were repeated during the lesson, some of which seemed to have a strong relationship with particular musical features. The primary aim of the analysis that follows is to explore relationships between a limited number of gestures and musical phrases over the course of the lesson, to determine the extent of the correspondence in these cases.

There has been very little research conducted on the consistency of connection between gesture and musical phrase. In his monograph on gesture in Hindustani music, Matt Rahaim broaches the subject, finding that in a performance by the vocalist Girija Devi, thirty out of thirty-four occurrences of a particular musical phrase were accompanied by a gesture where both hands curl and pivot around a small imaginary sphere (Rahaim, 2012, p. 65). In this case, however, Rahaim does not show the details of his 
analysis. Looking beyond Hindustani music, Marcelo Wanderley's (2002) study of clarinetists' ancillary gestures is perhaps the most detailed analysis of correspondence between musical phrase and gesture. Using a motion-capture system to record clarinetists' position data from repeated performances of the same composition, Wanderley found a strong correlation between a player's movements and sonic events across the different performances (Wanderley, 2002, p. 252). I aim in this study to discover whether a correspondence can be found in multiple renderings of the same musical phrase during a Karnatak vocal lesson. Four gesture/musical-feature pairings that show evidence of a relationship over the course of the lesson are analyzed. I do not attempt to prove correspondence between all gestures and the musical phrases with which they co-occur, but rather aim to explore the evolution of a limited number of gesture/musicalfeature pairings over the course of the lesson. Both correspondence and disagreement between gesture and musical phrase are explored as a means of understanding the factors that influence a gesture's dynamic form.

\section{MUSIC AND SHAPE}

In the analysis that follows, shape and trajectory of the teacher's right-hand movements are used as a basis from which to judge similarity and difference between gestures. The shapes are the traces left behind by the hand as it moves through time. These are rendered as lines using motion graphics software through the process of tracking and tracing the hand movements. The shape referred to when speaking of shape in music could similarly be imagined as the trace left by music as it moves through time. Shape in both music and movement is an abstraction, as shape does not require an extended time dimension, while physical movement and music cannot exist without it. Rolf Inge Godøy has referred to this relationship as paradoxical, describing the abstraction of shape from music as 'a privileged mode of representation' that 'produces more or less stable images of an otherwise ephemeral sonorous flux' (Godøy, 1997, p. 89). He argues that as long as these shapes are conserved as trajectories they retain information on the dynamic nature of musical sound or sound producing actions (Godøy, 1997, p. 99). In the analysis that follows I give visual examples of shapes traced by the moving hand and describe them predominantly as trajectories. The combination of these two modes of description affords the analysis of gestural correspondence and variation over the course of the lesson.

\section{ELEMENTS OF KARNATAK MUSIC}

The terms gamaka, svara, and rāga, although each used to describe a different aspect of Karnatak melody, are, in practice, inextricably intertwined. The word svara is used to refer to the theoretical pitch positions that exist in a rāga. These are spoken using the sargam syllables, Sa Ri Ga Ma Pa Da and Ni.[2] The term gamaka is often translated as ornament: however the two words are conceptually quite different. A gamaka is not an embellishment but rather is fundamental to both rāga and svara due to the fact that each svara must be played using one of the gamakas with which it is traditionally associated in the rāga being performed (Viswanathan, 1977, p. 31).

The rāga taught by TKV in this lesson is śankarābharanam. Considered an important rāga in the Karnatak tradition, it is often performed in contemporary concerts as the main item. The theoretical pitches of śankarābharanam lie at the same positions as those of the major scale in Western music. Karnatak music textbooks use the symbols S R2 G2 M1 P D2 N2 S to refer to the rāga's ärohana and avarohana (ascending and descending pitch progressions).[3] With Sa placed at G, these characters correspond to the pitches shown in Figure 1.

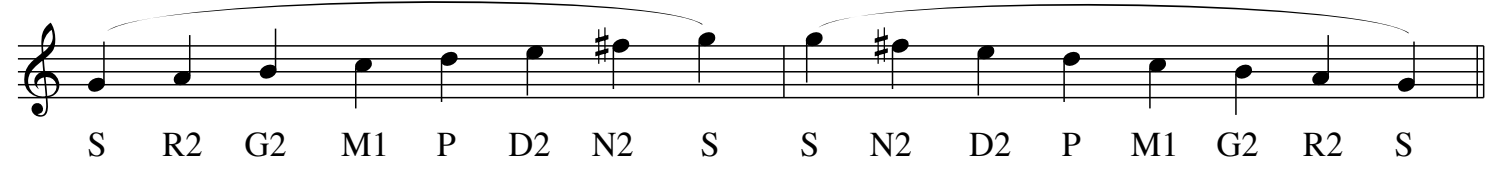

Fig. 1. The theoretical pitch position of rāga śankaräbharanam ärohana and avarohana.

The rāga, however, will never be played in the manner notated above as it lacks the gamakas required for it to communicate the mood (bhāva) with which it is traditionally associated. In śankaräbharanam only Sa and $\mathrm{Pa}$ are sung without gamakas. A basic rendition of the ärohana and avarohana of śankarābharanam performed with gamakas is shown in Figure 2.[4] 

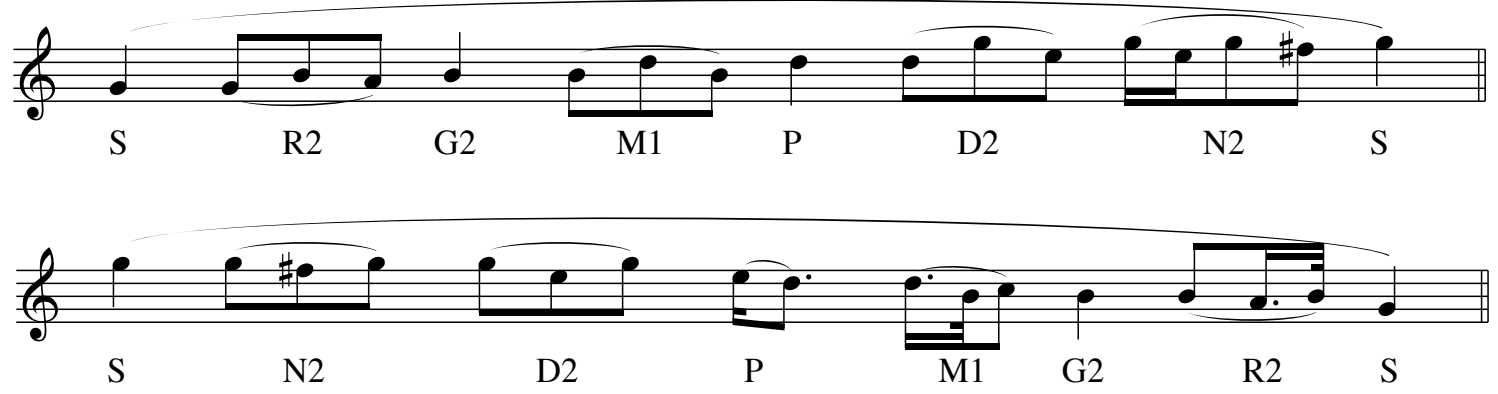

Fig. 2. A basic rendition of rāga śankarābharanam ārohana and avarohana showing the clusters of pitches that form the gamaka for each svara.

As can be seen in this transcription, the majority of svaras comprise more than one pitch. These clusters of pitches are gamakas, constituting small units of melodic movement on and between svaras. As we shall see in the analysis that follows, the form of a gamaka varies in performance, as it is dependent on both the speed of the phrase and the svaras that precede and follow it.

A vocalist improvising within rāga śankaräbharanam is not free to sing these svara/gamaka units in any order. For the mood (bhāva) to be communicated correctly the performance should include many characteristic phrases (prayōgas) (Interview with T.K.V. Ramanujacharlu, Srirangam, September 22nd 2011). As a result certain phrases reoccur many times during älāpana performance. In the vocal lesson analyzed here these repeated phrases afford us the opportunity to observe similarity and variation between gestures across many different performances of the same phrase.

\section{METHOD}

The fifteen-minute vocal lesson was recorded on a digital camera at twenty-five frames per second. Audio was recorded separately and synchronized to the video in Final Cut Pro 7 before being exported as a Quick Time movie. The movement of the teacher's hand was tracked and traced in After Effects motion graphics software. This allowed the trajectory of the hand to be viewed either as a developing line in a movie file, or as a static shape. The lesson structure, in which the teacher sang short phrases for imitation by the student, naturally parsed the music into phrases of between two and five seconds in length. These phrases were logged and transcribed into sargam notation, and the gestures that accompanied them were examined. Seven gestures that appeared to correspond to particular musical features were listed, and four of the more complex of these were subsequently analyzed in detail, looking at the development of the relationship between gesture and musical phrase over the course of the lesson.

The following section of this paper gives examples of these four gesture/musical-feature relationships. They are presented as figures showing pitch graphs created in Praat sound analysis software (Boersma \& Weenink, 2012) and transcription of the phrases into both Western staff notation and Indian sargam. Below these elements are placed still images of the traced hand gestures that co-occur with the musical phrases. Each example is followed by an analysis of the gesture/musical-feature relationship over the duration of the fifteen-minute lesson. 


\section{ANALYSIS}

\section{Circular Oscillation Gesture}

Trajectory - circular or oval

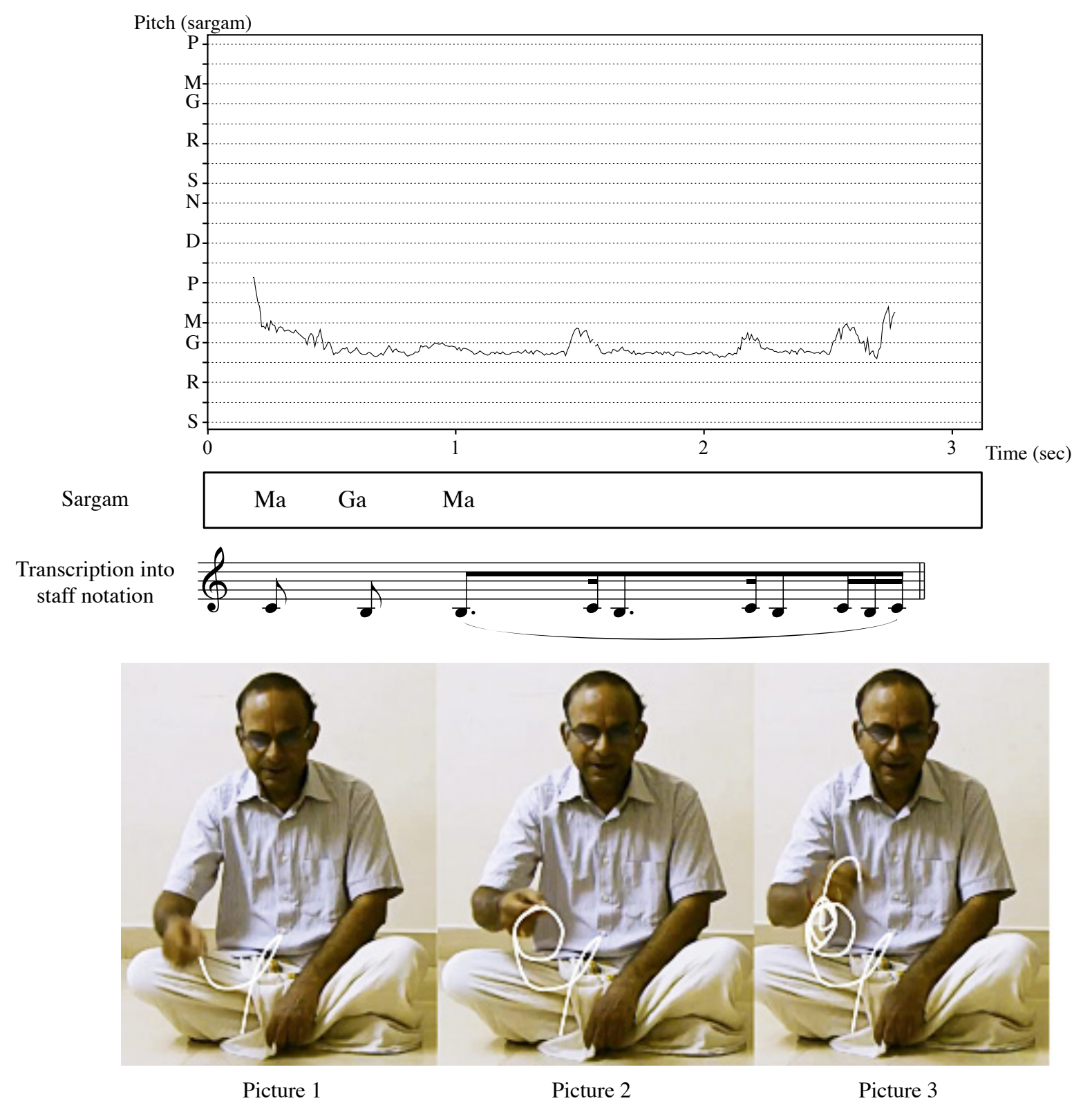

Fig. 3. An example of the circular oscillation gesture $2{ }^{\prime} 26^{\prime \prime}$ into the lesson, shown with the musical phrase with which it co-occurs represented as a Praat pitch graph, transcription into sargam, and Western staff notation. The three images show the beginning, middle, and end of the gesture respectively.

This circular gesture frequently co-occurs with the slow vocal oscillation that is used to sing Ma in $r \overline{a g} a$ śankaräbharanam, a type of gamaka referred to as kampita in Karnatak music theory (Viswanathan, 1977, p. 33). In Figure 3, Picture 1 coincides with the initial Ma-Ga of the phrase. The teacher's gesture slightly anticipates the sound, completing one loop of the circle before the vocal oscillation begins (see Picture 2). A total of five circles are made, the last of which develops into an upward loop (see Picture 3) that matches the final upward pitch movement at the end of the phrase. 
The prolonged Ma sung with a slow oscillation occurs twenty-three times during the lesson. On thirteen of these occasions it co-occurs with the circular gesture shown in Figures 3 and 5. Eight of the instances in which a different gesture is performed take place during a section of the lesson from 3' 52 " to 5'58' where the teacher attempts to correct the student's rendition of the svara sequence that precedes the $\mathrm{Ma}$. On these occasions $\mathrm{Ma}$ is instead accompanied by a slight and indistinct gesture that marks only a single beat in place of the repeated circles that had been traced in ten of the eleven previous renditions. One possible explanation for this abrupt change is that the teacher's focus shifts from the phrase as a whole to only the part that is being sung incorrectly, and as a result his engagement with the oscillatory movement on $\mathrm{Ma}$ is lost. An alternative interpretation is that by avoiding gesturing on $\mathrm{Ma}$ he is de-emphasizing it in order to help the student focus on the part of the phrase that requires attention.

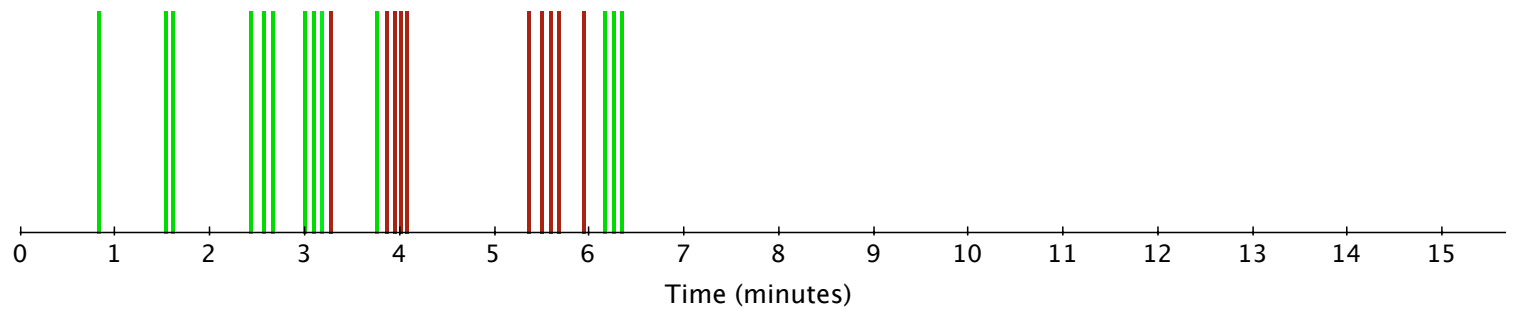

Fig. 4. The green and red lines represent every occurrence of the oscillating Ma over the course of the fifteen-minute lesson. The thirteen green lines indicate the instances of Ma that co-occur with the circular gesture, while the ten red lines represent those that are accompanied by other gestures.

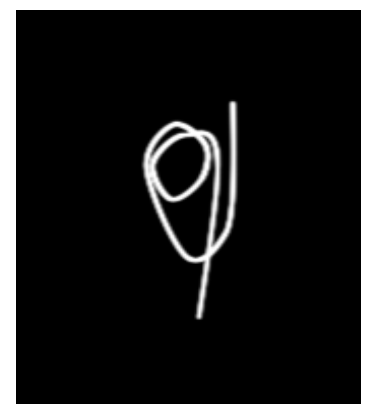

1'37"

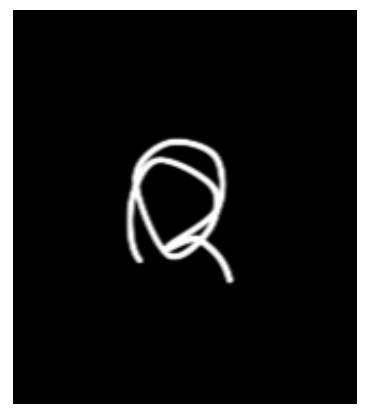

2'34"

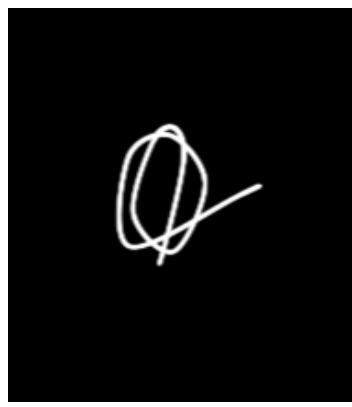

6'16"

Fig. 5. Traces of the circular gesture that co-occurs with Ma at 1'37', 2'34", and 6'16", illustrating the extent of the correspondence across the lesson. While the shapes of the gestures are not identical, they all show a repeated circular or oval trajectory. 


\section{Lateral Loop Gesture}

Trajectory - movement out to the side followed by a loop back to the center

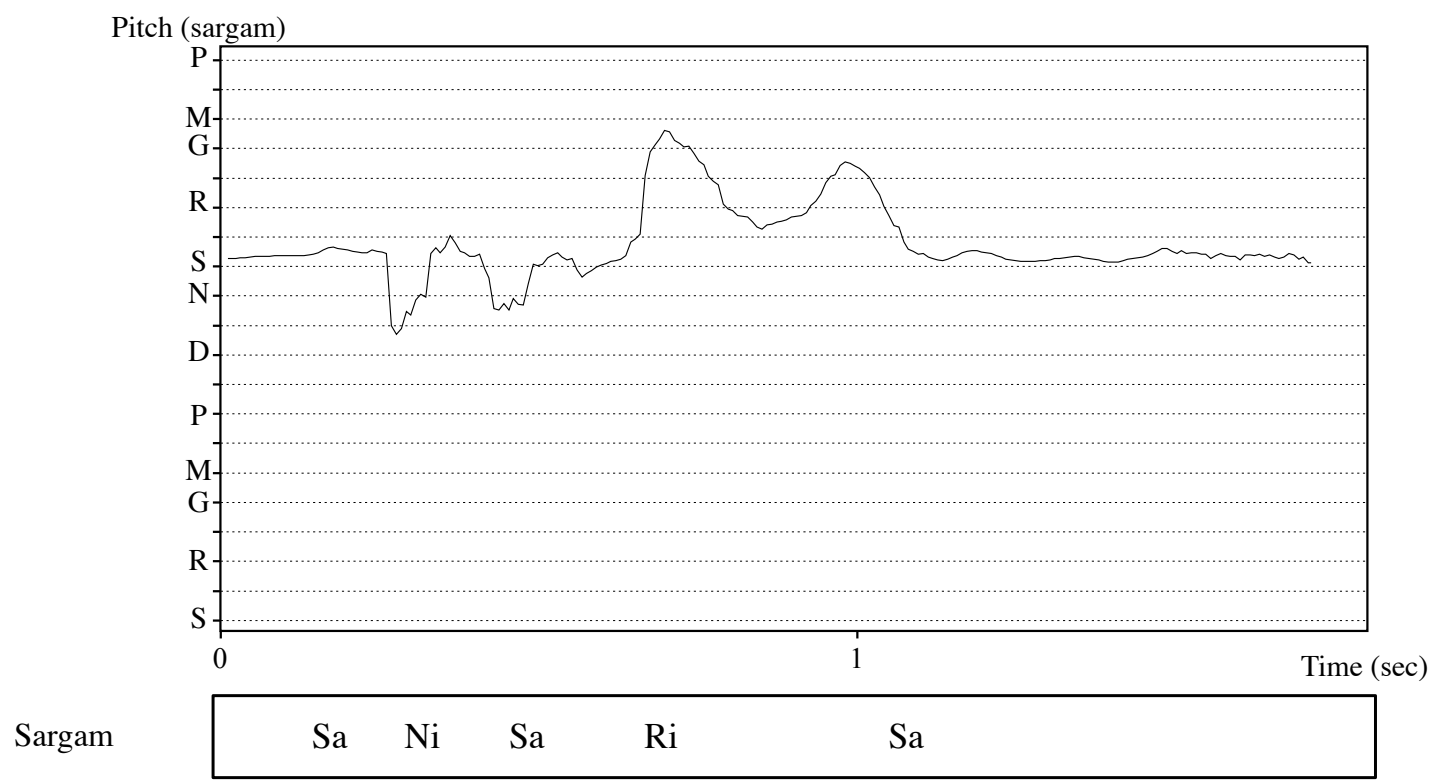

Transcription into staff notation

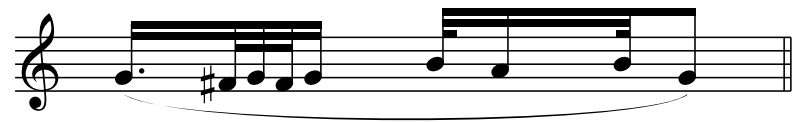

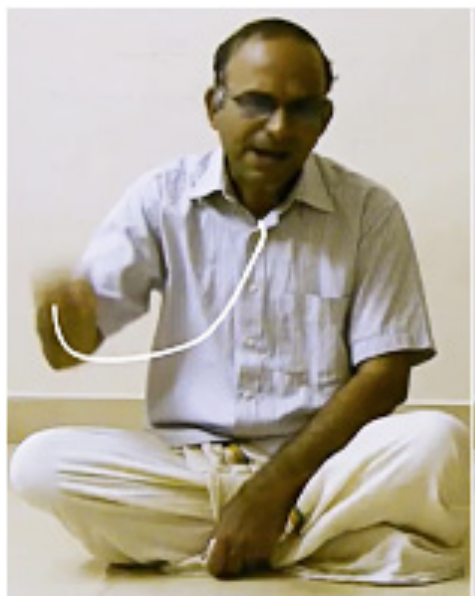

Picture 1

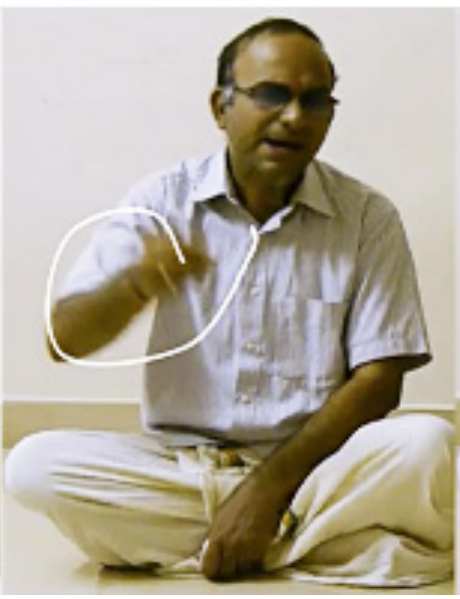

Picture 2

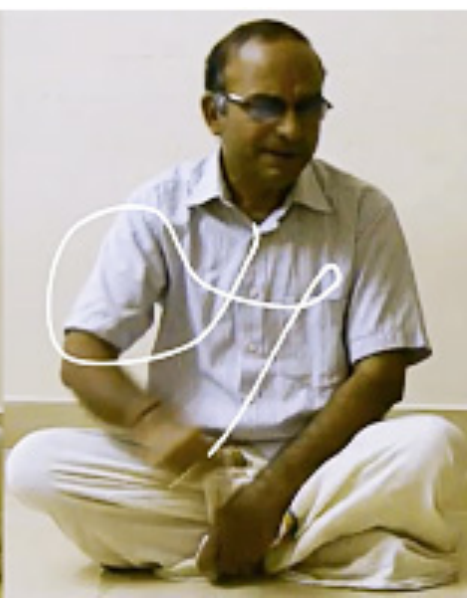

Picture 3

Fig. 6. An example of the lateral loop gesture occurring 8 ' $28^{\prime \prime}$ into the lesson together with the svara sequence $\mathrm{Sa}-\mathrm{Ri}-\mathrm{Sa}$.

This gesture often co-occurs with the svara sequence Sa-Ri-Sa and is particularly associated with the gamaka used to sing a prolonged Ri followed by a fall to Sa. A significant feature of this particular gesture/musical-feature pairing is that the stressed svara/gamaka unit Ri coincides with the sharp movement of the hand away from the center of the body. This movement can be seen in Picture 1 of Figure 6. As the hand loops round, its descent synchronizes with the fall in pitch onto the final Sa (see Picture 2). Picture 3 shows a gestural flourish that occurs as the teacher completes the phrase.

The svara sequence Sa-Ri-Sa occurs a total of twenty-one times during the lesson, fourteen of which co-occur with the lateral loop gesture. 


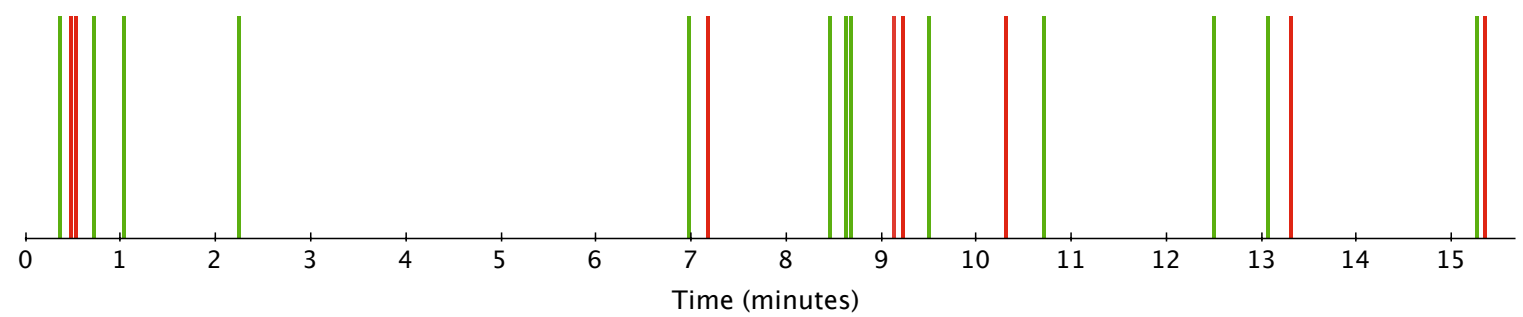

Fig. 7. The green and red lines represent every appearance of Sa-Ri-Sa over the course of the lesson. The fourteen green lines indicate the instances of the phrase that co-occur with the lateral loop gesture, while the seven red lines show those that are accompanied by another gesture.

Of the seven occasions that the phrase Sa-Ri-Sa is performed without the lateral loop gesture, three occur while the teacher is correcting errors in the student's performance. On a further two occasions the gesture is altered when the sequence Sa-Ri-Sa is placed at the end of a different svara sequence. The result of this change of musical context is that the gesture becomes a forward rather than a lateral motion. The traces shown in Figure 8 illustrate the variation that occurs in the dynamic form of the gesture when the svara sequence with which it co-occurs is placed at the end of a longer phrase.

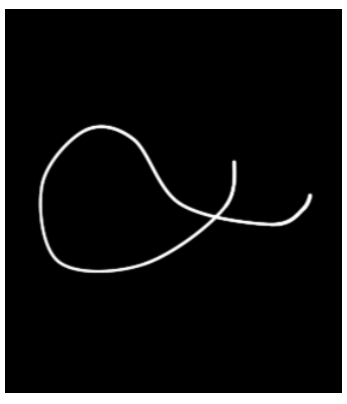

$8^{\prime} 28^{\prime \prime}$

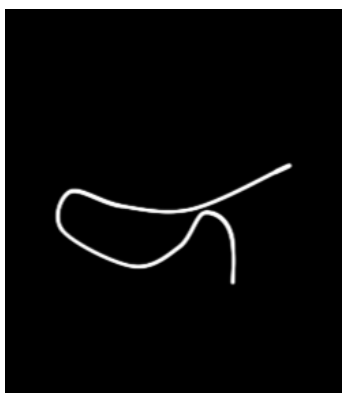

$8^{\prime} 41^{\prime \prime}$

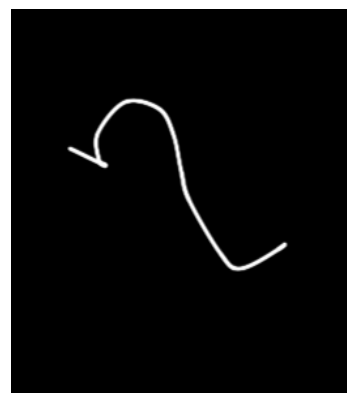

9'14"

Fig. 8. Traces of the hand movements that co-occur with Sa-Ri-Sa at 8'28', 8'41", and 9'14" showing the influence of the phrase as a whole on the gesture. In the first two images the phrase sung consists only of the svaras Sa-Ni-Sa-Ri-Sa. However, at 9'14" Sa-Ri-Sa occurs at the end of a long phrase, and the gesture loses its distinctive trajectory of a move out to the side and return to center.

\section{Upward Throw Gesture}

Trajectory - rapid ascending and descending motion forming a pointed oval shape (Figure 9)

This gesture frequently co-occurs with the svara sequences Pa-Da-Ni-Sa and Sa-Ri-Ga-Ma, both of which feature a rapidly oscillating gamaka within an ascending pitch sequence. In Figure 9 the gesture is timed so that the highest point of the arc coincides with the vocal leap up from D to G that forms Da. This can be seen in the high peaks of the traced gesture in Picture 1 and Picture 3 of Figure 9, which coincide with the $\mathrm{Da}$ within the phrase Pa-Da-Ni-Sa on each of the two occasions that it is sung. 


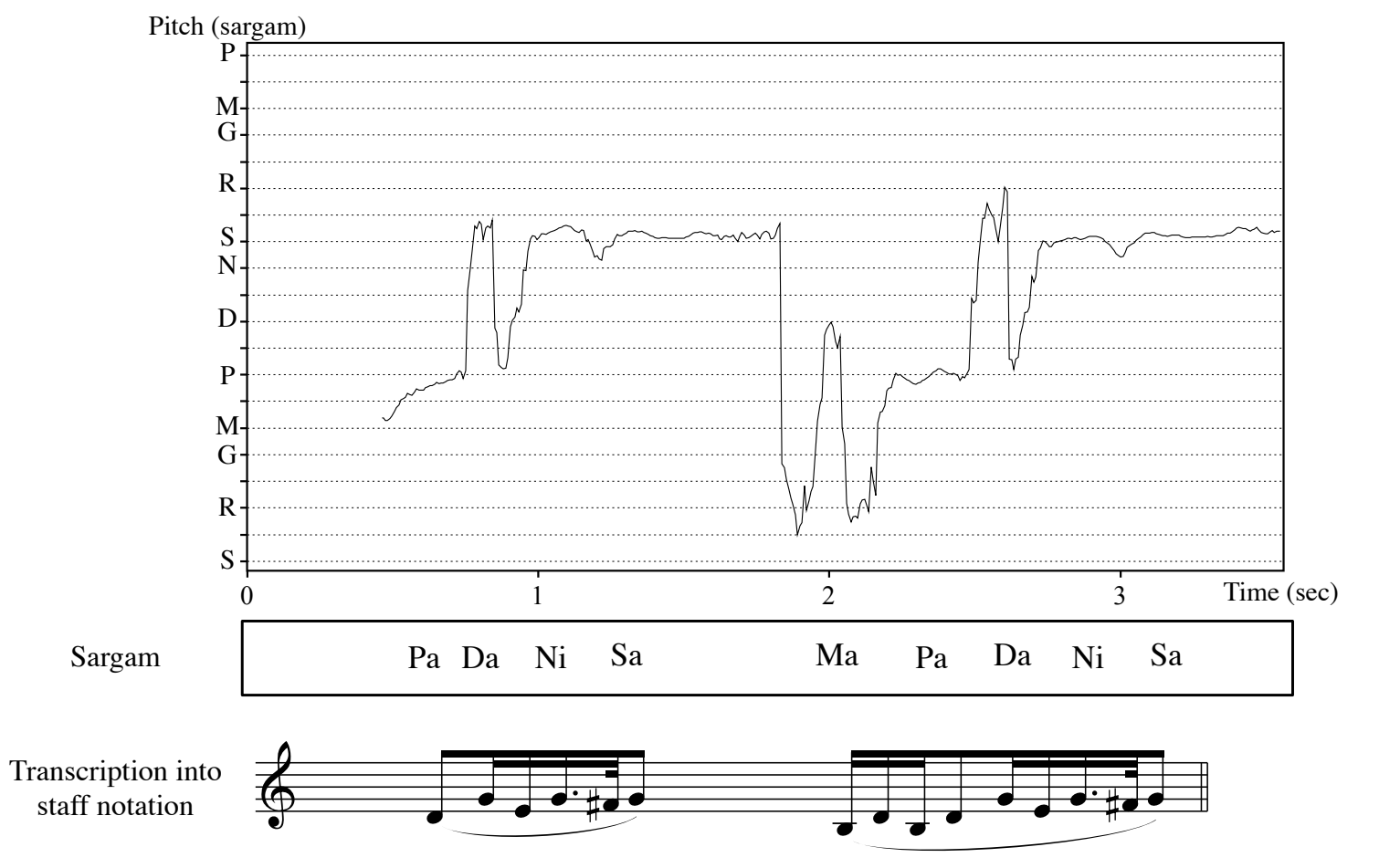

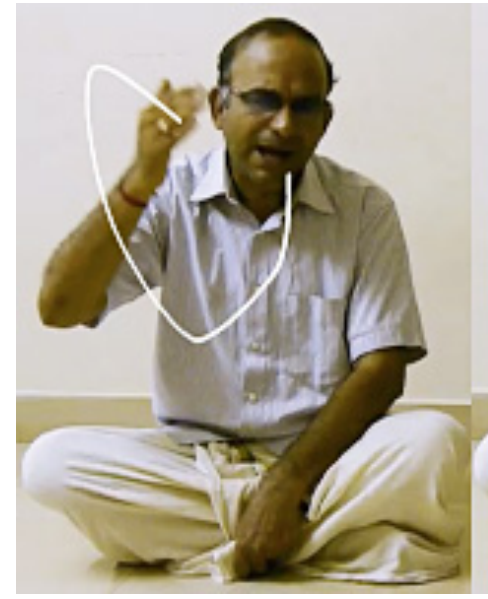

Picture 1

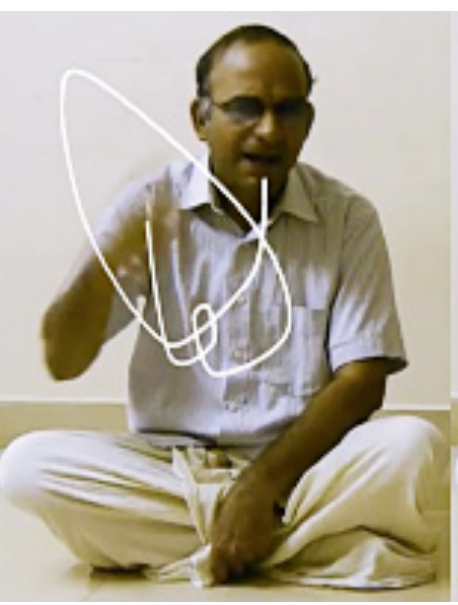

Picture 2

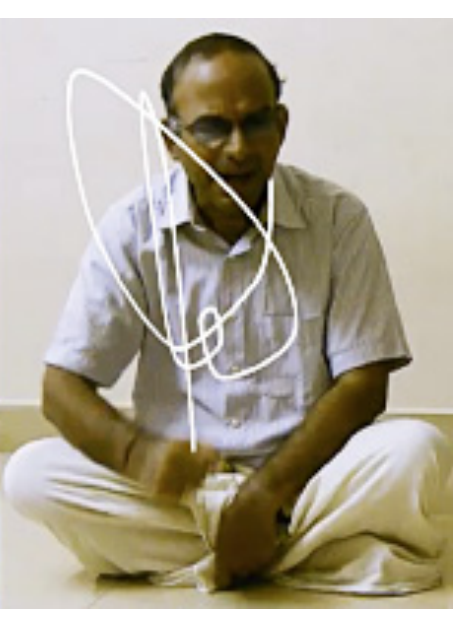

Picture 3

Fig. 9. Upward throw gesture occurring 7'46" into the lesson together with the phrase Pa-Da-Ni-Sa. The same gesture frequently co-occurs with the phrase Sa-Ri-Ga-Ma.

There are forty examples of the svara sequence Sa-Ri-Ga-Ma in the lesson, thirty of which co-occur with the upward throw gesture. On these occasions the amplitude of the gesture is large and timed so that the furthest edge of the movement away from the center of the body coincides with the double oscillation used to sing Ri-Ga. 


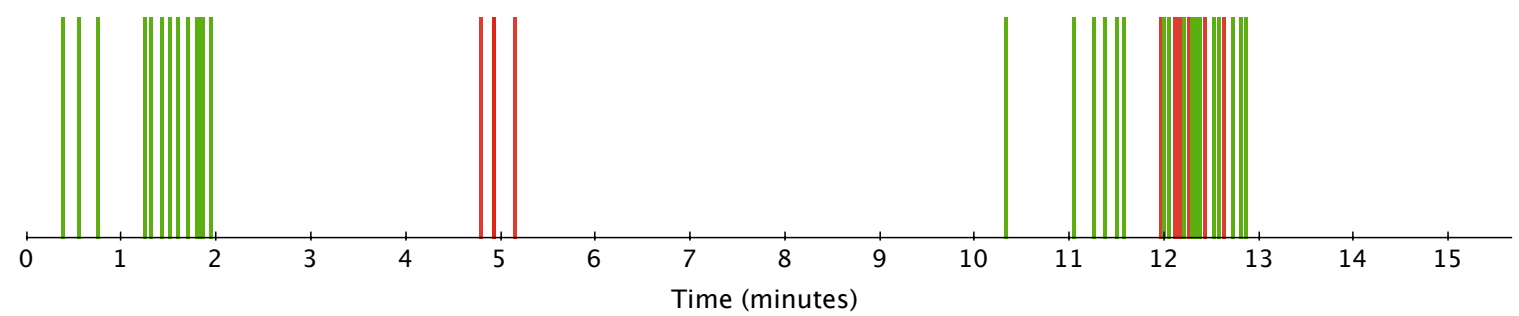

Fig. 10. The green and red lines represent every occurrence of the svara sequence Sa-Ri-Ga-Ma over the course of the lesson. The thirty green lines indicate the instances of the sequence that co-occur with the upward throw gesture, while the ten red lines represent those that are accompanied by a different gesture.

As in the two previous analyses the gesture/musical-feature correspondence breaks down when either the teacher corrects the student's performance, or an extra phrase is added to the svara sequence. For example at 4'48" the upward throw gesture is absent when the phrase Pa-Da-Pa-Ma-Ga is added to the end of Sa-RiGa-Ma (see Figure 12). The phrase is accompanied instead by a lateral back and forth movement of the hand, which although retaining the same points of emphasis is clearly a different gesture. Once again the extension of the overall phrase has a strong effect on the dynamic form of the gesture.

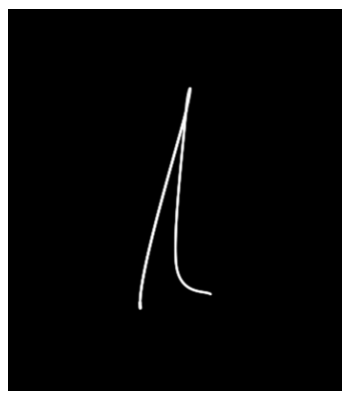

$0^{\prime} 45^{\prime \prime}$

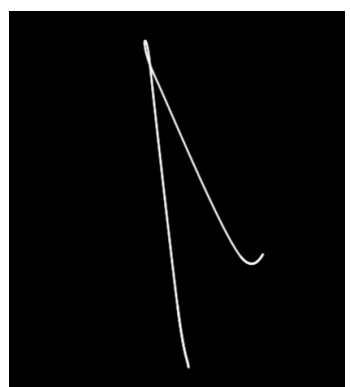

$1^{\prime} 15^{\prime \prime}$

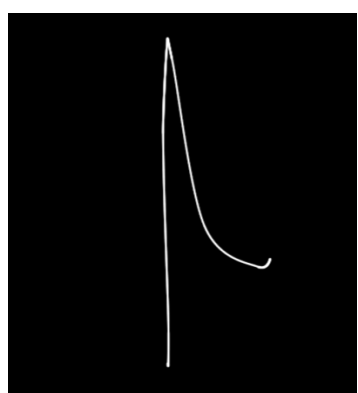

1 '26"

Fig. 11. Traces of the hand movements that co-occur with Sa-Ri-Ga-Ma at 0'45", 1'15', and 1'26". In each case the phrase ends with only Sa-Ri-Ga-Ma-Ga.

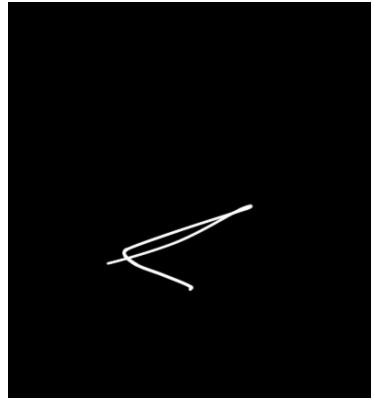

4'48"

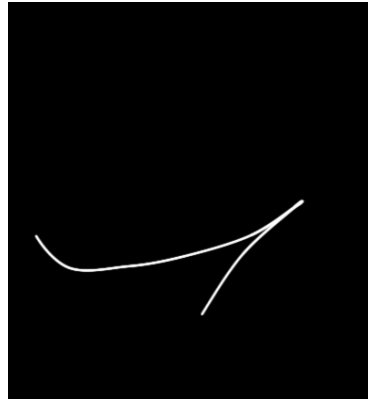

5'09"

Fig. 12. Traces of the hand movements that co-occur with Sa-Ri-Ga-Ma at 4'48", and 5'09". At this point in the lesson the extra phrase Pa-Da-Pa-Ma-Ga is sung at the end of the Sa-Ri-Ga-Ma sequence, and the gesture alters to become a lateral back and forth movement.

\section{Downward Throw Gesture}

Trajectory - rapid descending and ascending motion forming a pointed oval shape 


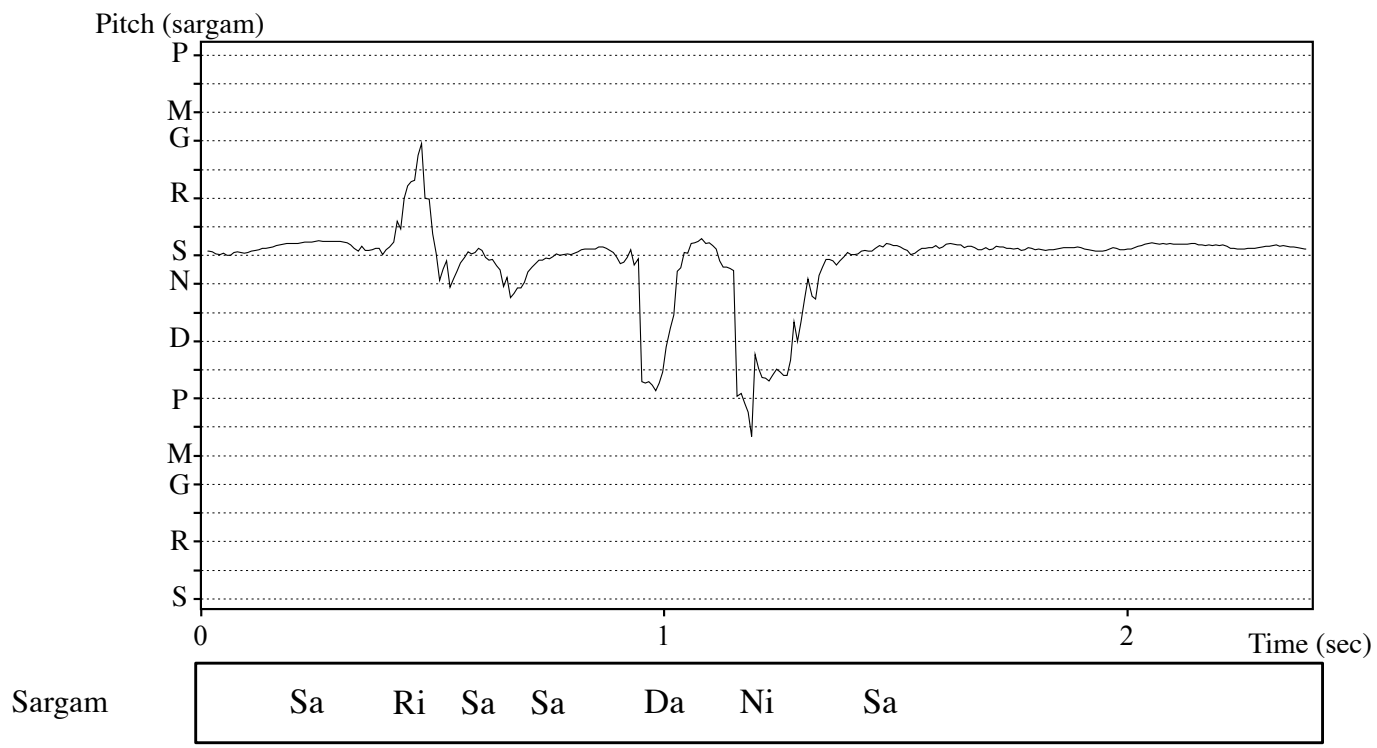

Transcription into staff notation

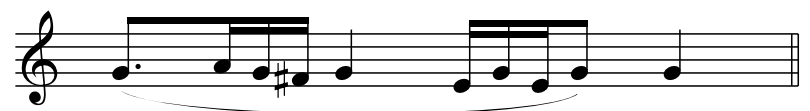

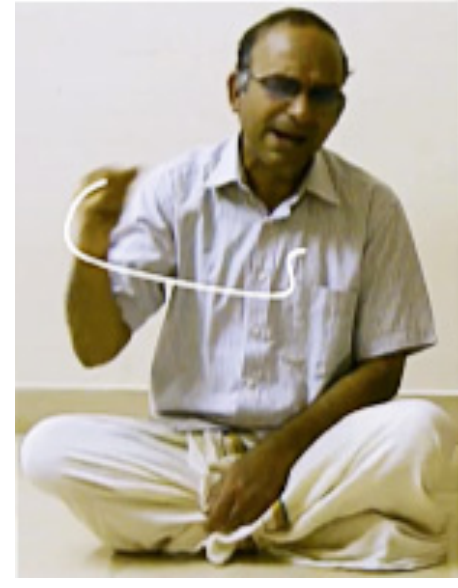

Picture 1

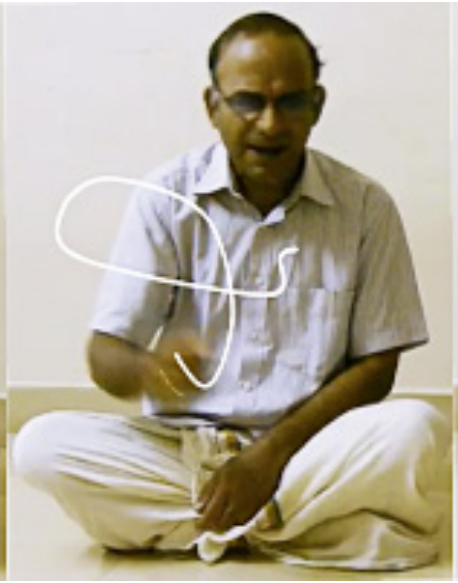

Picture 2

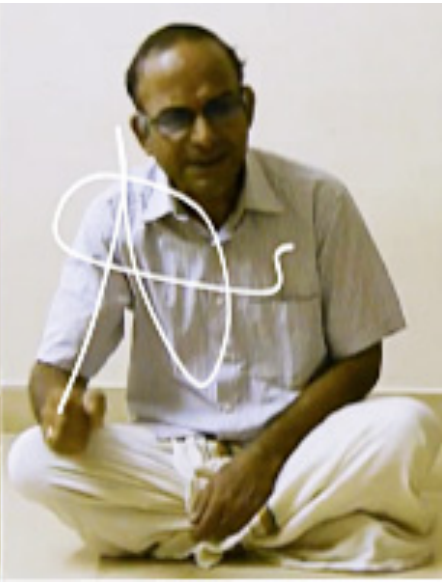

Picture 3

Fig. 13. Downward throw gesture occurring 8'33" into the lesson together with the svara sequence Sa-DaNi-Sa.

The svara sequence Sa-Da-Ni-Sa in the second half of this example co-occurs with the downward throw gesture shown in Figure 13, and is particularly associated with the rapidly oscillating gamaka used to sing Da-Ni. Picture 1 of Figure 13 shows the lateral hand movement that occurs together with the opening Sa Ri $\mathrm{Sa} \mathrm{Sa}$ of the phrase. The bottom of the downward throw gesture in Picture 2 coincides with the first $\mathrm{E}$ of $\mathrm{Da}$, before rebounding up for the penultimate G. Picture 3 shows the hand returning to a neutral position at the end of the phrase. 


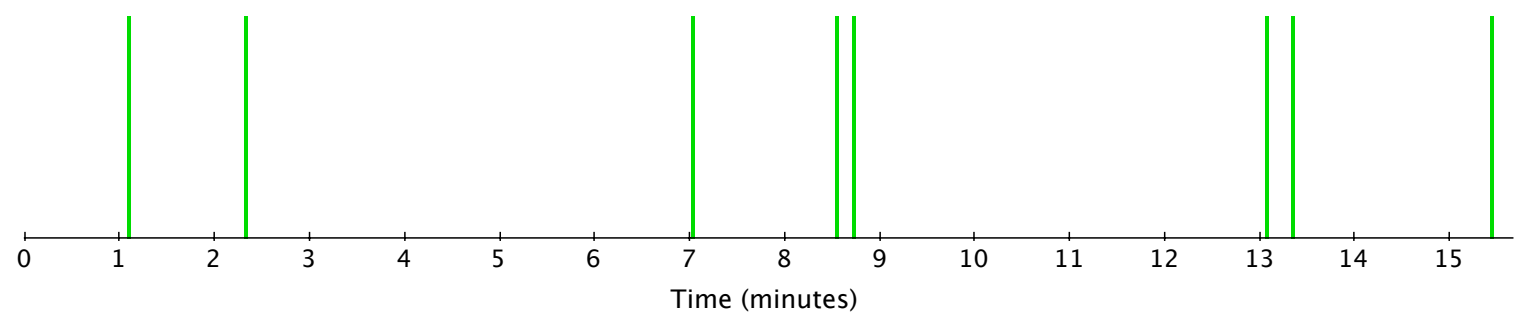

Fig. 14. The green lines represent every occurrence of the svara sequence Sa-Da-Ni-Sa over the course of the lesson. The eight green lines indicate instances in which the svaras co-occur with the downward throw gesture. The phrase does not appear in the lesson accompanied by a different gesture.

The svara sequence Sa-Da-Ni-Sa occurs only eight times during the lesson, but on every occasion is accompanied by the downward throw gesture. The sequence forms the second half of an important characteristic phrase (prayōga) in rāga śankarābharanam that is often used to bring a section of the àläpana to a close. As a result the sequence appears each time with little variation, and therefore its association with the downward throw gesture is remarkably stable. The lowest point of the movement in this gesture coincides with the first $\mathrm{E}$ of the rapid double oscillation between $\mathrm{E}$ and $\mathrm{G}$ used to sing Da-Ni. In common with the upward throw gesture previously discussed, the greatest velocity and amplitude of the downward throw gesture coincides with a gamaka comprising wide and fast oscillations in pitch. Viewed from an embodied perspective this coincidence raises the possibility that in these cases the upward or downward impetus of the hand is linked to the effort that is required to sing these rapid oscillatory gamakas. A discussion of how gestures may relate to the physicality of Karnatak vocal technique is taken up in the final section of this paper following a summary of the observations derived from the analysis.

\section{SUMMARY AND DISCUSSION}

This analysis has shown four examples of correspondence between gestures and short svara sequences, in which the gesture/musical-feature pairing occurs repeatedly over the course of the lesson. Stressed svaras and gamakas formed from fast and wide oscillations are particularly related to the outer points of trajectories travelling away from the center of the body. However, at several points in the analysis the gesture alters when the musical feature with which it is linked appears in a different musical context, demonstrating that the form of the gesture is not solely determined by a particular sonic feature but is also influenced by the phrase as a whole. Nevertheless, when the gesture does change under these conditions the oscillatory gamakas still tend to be marked in the new hand movement. The remainder of this paper will discuss two significant influences on the dynamic form of gesture suggested by these observations: the phrase as a whole, and discrete musical features such as oscillatory or stressed gamakas.

The holistic influence of the entire phrase on an individual gesture is seen at several points in the analysis. An example can be seen in Figures 11 and 12 where a gesture performed on multiple consecutive occasions with the same musical feature is considerably altered when an extra sequence is added to the phrase. This gesture in turn becomes part of a new gesture/musical-feature pairing in the context of the altered overall phrase. Gesture here seems to act as a schema of the phrase as a whole, and could perhaps be viewed as a kinetic control system for the complex and detailed array of patterns encountered in the music (see Bregman, 1994, for a discussion of schemata in auditory analysis). To build on this observation, further studies should be conducted in order to gather more data on gesture/musical-feature relationships over several lessons given by a single performer in both śankarābharanam and other rāgas. This would provide the evidence required to determine whether gesture/musical-feature pairings persist over different lessons, and also develop a clearer model of the circumstances in which gesture changes.

The second influence on gesture suggested by this analysis is the presence of oscillatory or stressed gamakas. It is a feature of gamakas that they often require fast and complex vocal fluctuations, sometimes moving rapidly back and forth at intervals of a minor third or more. In the vocal lesson examined here the initial vocal movements of these fast oscillations are frequently tied to the extremities of gestures. A possible explanation for this link is that the hand motion corresponds to the physical movement that produces the sound. In vocal performance, sound producing actions lie predominantly in the larynx, thorax, and diaphragm. Pitch change is achieved largely through the adjustment of vocal fold tension in the larynx. This is determined by the relative positions of the cricoid, thyroid, and arytenoid cartilages, which 
are adjusted by the cricothyroid and strap muscles (Erickson, Baer, \& Harris, 1983, p. 279). Studies have indicated that during singing, the cricothyroid muscles control pitch frequency while the strap muscles control aspects of voice production required to produce effects such as vibrato, trill, and glissando (Roubeau, Chevrie-Muller, \& Saint Guily, 1997, p. 459). By placing your hand against the top of your throat it is possible to feel this movement as the cartilage shifts up and down with changes in pitch and exertion. When a vocalist sings in the Karnatak style, oscillations and leaps in pitch are created, in part, by fluctuations and exertions in the larynx. The relationship between wide vocal oscillations and extremes of gestural movement found in this study raises the possibility that the gestures observed could be linked to the intensity of muscular movement in the larynx of the vocalist. This could suggest that the anticipation and performance of physical exertion patterns resonate through the entire body of the vocalist, and show themselves in the hand gestures that co-occur with vocalization. This hypothesis does not preclude the significance of other influences on gesture, such as kinetic analogy, expressive communication, and unconscious imitation of a teacher's gestures. It does, however, involve a shift in emphasis back to the body and 'sound-producing actions' (Godøy, 2003) as the origin of the kinetic play that forms such an important part of music (see Baily, 1985 and Godøy, 2003). In order to test the hypothesis that sound producing actions co-stimulate the hand gestures that accompany them, the intensity of movement in the larynx of the vocalist should be examined for correlation to gestural features. In addition, further studies should be conducted on gesture in vocal lessons and performances given by other Karnatak vocalists. Such research would clarify whether the majority of performers exhibit a similar correspondence between gesture and sonic event, and also contribute to a model of the factors that determine gestural similarity and variation.

In this analysis, the shape and trajectory of hand movements have provided useful information with which to judge gestural similarity and difference. The traces of movement through time rendered visible as lines have afforded observation and communication of the relationship between physical movement and musical features at both detailed and larger-scale levels. Although parameters such as position, velocity, and acceleration would provide more detailed movement data, shape and trajectory can be valuable tools in the analysis of gesture in musical performance.

\section{ACKNOWLEDGEMENTS}

I would like to thank T.K.V. Ramanujacharlu and his students for their contributions to this study. I am also grateful to Udo Will, Martin Clayton, Laura Leante, and Barley Norton for their advice and helpful comments on the text. The research was generously supported by the British Library, which houses the video footage created during the project.

\section{NOTES}

[1] In Karnatak music, àläpana is an improvisation on one or more rāgas performed before a composition.

[2] Sargam is a relative pitch system similar to solfège. Sa can be placed on any pitch, although male vocalists tend to place Sa between B3 and C4 sharp, and female vocalists between F4 sharp and G4 sharp. In this lesson the teacher is singing with Sa placed at G in order to accommodate the female student's vocal range.

[3] The numbers placed after the svara situate it within a division of the octave into twelve pitches. R2 is two semitones up from S, and M1 is one semitone up from G2. The system is commonly used in Karnatak music theory when referring to the árohana and avarohana of a rāga. However, the classification is approximate, as Karnatak music employs microtones outside of these twelve divisions (Kassebaum, 1999).

[4] The transcription of śankaräbharanam rāga in Figure 2 is based on a demonstration given by T.K.V. Ramanujacharlu during an interview recorded in Srirangam in September 2011. Throughout this paper the transcriptions have been written with Sa placed at G, the pitch at which the lesson was sung.

\section{REFERENCES}


Baily, J. (1985). Music structure and human movement. In: P. Howell, I. Cross \& R. West (Eds.), Musical Structure and Cognition. London: Academic Press, pp. 237-258.

Bregman, A.S. (1994). Auditory Scene Analysis: The Perceptual Organization of Sound. Cambridge, Mass.: MIT Press.

Boersma, P. \& Weenink, D. (2012). Praat: doing phonetics by computer [Computer program]. Version 5.3.11, retrieved 27 March 2012 from http://www.praat.org/

Clayton, M. (2005). Communication in Indian raga performance. In: D. Miell, R. MacDonald, \& D. J. Hargreaves (Eds.), Musical Communication. Oxford: Oxford University Press, pp. 361-382.

Clayton, M. (2007). Time, gesture and attention in a Khyāl performance. Asian Music, Vol. 38, No. 2, pp. 71-96.

Erickson, D.M., Baer, T., \& Harris, K.S. (1983). The role of the strap muscles in pitch lowering. In: D. Bless \& J. Abbs (Eds.), Vocal Fold Physology: Contemporary Research and Clinical Issues. San Diego: College-Hill Press, pp. 279-285.

Fatone, G., Clayton, M., Leante, L., \& Rahaim, M. (2011). Imagery, melody and gesture in cross-cultural perspective. In: A. Gritten \& E. King (Eds.), New Perspectives on Music and Gesture. Farnham: Ashgate, pp. 203-220.

Godøy, R.I. (1997). Knowledge in music theory by shapes of musical objects and sound-producing actions. In: M. Leman (Ed.), Music, Gestalt, and Computing. Berlin: Springer, pp. 89-102.

Godøy, R.I. (2003). Motor-mimetic music cognition. Leonardo, Vol. 36, No. 4, pp. 317-319.

Godøy, R.I., \& Leman, M. (Eds.). (2010). Musical Gestures : Sound, Movement, and Meaning. London: Routledge.

Gritten, A., \& King, E. (Eds.). (2006). Music and Gesture. Aldershot: Ashgate.

Gritten, A., \& King, E. (Eds.). (2011). New Perspectives on Music and Gesture. Farnham: Ashgate.

Kassebaum, G.R. (1999). Karnatak raga. In: A. Arnold (Ed.), The Garland Encyclopedia of World Music, Vol. 5, South Asia: The Indian Subcontinent. New York: Garland, pp. 89-109.

Leante, L. (2009). The lotus and the king: imagery, gesture and meaning in a Hindustani rāg. Ethnomusicology Forum, Vol. 18, No. 2, pp. 185-206.

Rahaim, M. (2008). Gesture and melody in Indian vocal music. Gesture, Vol. 8, No. 3, pp. 325-347.

Rahaim, M. (2012). Musicking Bodies: Gesture and Voice in Hindustani Music. Middletown, Conn.: Wesleyan University Press.

Roubeau, B., Chevrie-Muller, C., \& Saint Guily, J.L. (1997). Electromyographic activity of strap and cricothyroid muscles in pitch change. Acta oto-laryngologica, Vol. 117, No. 3, pp. 459-464.

Viswanathan, T. (1977). The analysis of rāga ālāpana in South Indian music. Asian Music, Vol. 9, No. 1, pp. 13-71.

Wanderley, M. (2002). Quantitative analysis of non-obvious performer gestures. In: I. Waschmuth \& T. Sowa (Eds.), Gesture and Sign Language in Human-Computer Interaction. Berlin: Springer, pp. 241-253. 